\title{
Design of a Compact Circularly Polarized Folded Square Patch Antenna for GPS Applications
}

\author{
T. Sindhu', C. Manjula ${ }^{2}$ \\ ${ }^{1}$ PG Scholar, Adhiyamaan College of Engineering (Autonomous), Hosur, Tamil Nadu, India \\ ${ }^{2}$ Assistant Professor /Department of ECE, Adhiyamaan College of Engineering (Autonomous), Hosur, Tamil Nadu, India
}

\begin{abstract}
A compact circularly polarized (CP) folded square patch antenna is developed for global positioning system (GPS) receivers. Theantennais designed on the flame resistant(FR4) substrate of relative permittivity 4.4 and thickness $1.6 m m . B y$ connecting four different length of meander strips to the four edges of the patch of a single coaxial feed square patch antenna are folded to achieve a circularly polarized antenna. The CP antenna has an advantage of greater flexibility in orientation angle between the transmitter and receiver. The proposed folded patch antenna receives the GPS operating frequency of $1575 \mathrm{MHz}$. Due to its compact size, simple structure and less expensive, the proposed antenna can be used for GPS applications. The antenna parameters is simulated by HFSS.
\end{abstract}

Keywords: Folded square patch antenna, Circularly polarized antenna, Coaxial probe feeding,FR4 substrate, global positioning system.

\section{Introduction}

An antenna is an electronic device that converts radio frequency $(\mathrm{RF})$ electric current to electromagnetic waves that are radiated into free space. Thus antennas plays a very important role in wireless communications. Circularly polarized folded patch antenna are widely used in global positioning systems(GPS), radio frequency identification systems(RFID) and vehicle communication devices.

GPS is a space-based navigation system that provides location and time information in all weather conditions. It plays a very important role in tracking and location mapping in most of the ships, automobiles and in aircrafts by using triangulation method.GPS receivers composed of an antenna, receiver processors and a highly stable clock.GPS antenna requires right hand circular polarization, which enables a flexible orientation angle between the transmitter and receiver. Generally single feed and dual feed are used in patch antennas. As compared to the dual feed patch antennas, single feed provides a larger circularly polarized bandwidth but it should require a larger ground plane for the feeding network.

Many industry requires a high performance, compact size and low cost antenna. To meet the miniaturization requirements, folded patch GPS antenna is designed with FR4 substrate. This antenna operates in right-hand circular polarization (RHCP) wave in two orthogonal linear resonant modes. Folded patch antenna with different ground planes are designed and simulated to verify the effectiveness of the antenna. No complex feeding network is required. The final design is compact and inexpensive. Details of the proposed GPS antenna design and its performance are discussed.

\section{Antenna Design}

The proposed GPS antenna is printed on two layers of the FR4 substrate. The slotted square patch on layer 1 are connected to layer 2 via four holes namely P,Q,R,S at the edges of the square patch.

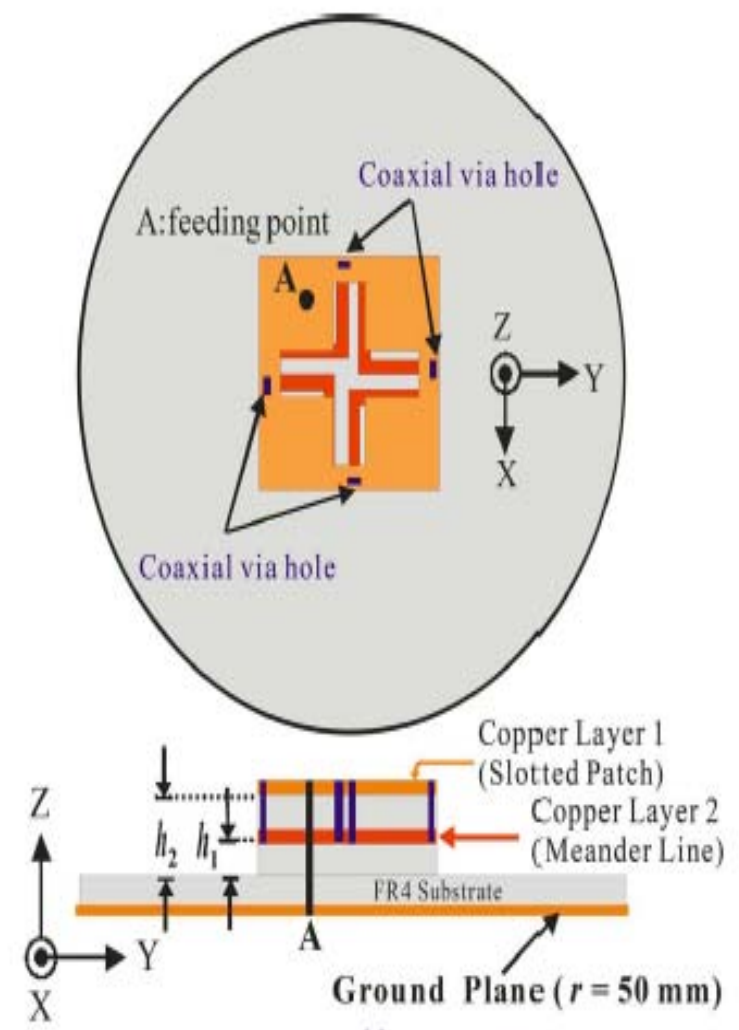

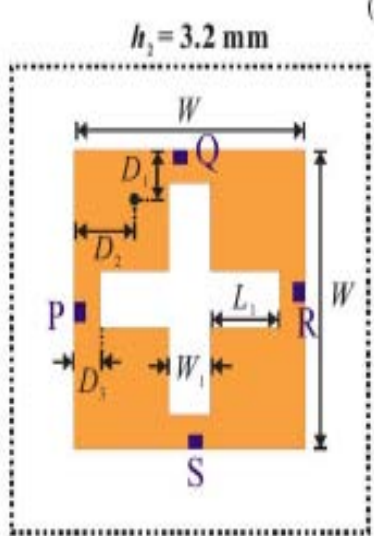

(b)

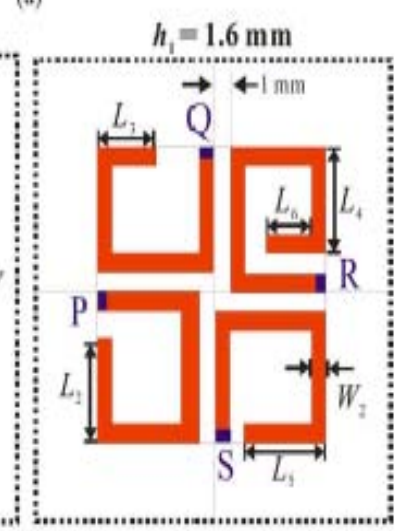

(c) 


\section{International Journal of Science and Research (IJSR) \\ ISSN (Online): 2319-7064}

Index Copernicus Value (2013): 6.14 | Impact Factor (2014): 5.611

Table 1: Dimension of the proposed GPS antenna

\begin{tabular}{|c|c|c|c|}
\hline Parameters & Values $(\mathrm{mm})$ & Parameters & Values $(\mathrm{mm})$ \\
\hline $\mathrm{W}$ & 15 & $\mathrm{~L}_{1}$ & 4.2 \\
\hline $\mathrm{W}_{1}$ & 2.8 & $\mathrm{~L}_{2}$ & 5 \\
\hline $\mathrm{W}_{2}$ & 1 & $\mathrm{~L}_{3}$ & 4 \\
\hline $\mathrm{D}_{1}$ & 2 & $\mathrm{~L}_{4}$ & 5.5 \\
\hline $\mathrm{D}_{2}$ & 3 & $\mathrm{~L}_{5}$ & 5.2 \\
\hline $\mathrm{D}_{3}$ & 1.5 & $\mathrm{~L}_{6}$ & 3 \\
\hline $\mathrm{h}_{1}$ & 1.6 & $\mathrm{~h}_{2}$ & 3.2 \\
\hline
\end{tabular}

The strips front end are connected to the holes using short wires. Here circular ground plane of $\operatorname{radius}(\mathrm{r})=50 \mathrm{~mm}$ is used. A larger ground plane will increase the gain of the antenna.

\section{A. Radiation Mechanism}

The radiating patches are folded to provide excitation in different resonant modes. The current flows from layer 2 to layer 1 . The circular polarization can be achieved only when the magnitude of the two field components are similar and their time difference is an odd multiple of 90 degrees. The circular polarization can be achieved when,

$$
\begin{aligned}
\left|E_{\theta}\right| & =\left|E_{\phi}\right|, \\
\angle E_{\phi}-\angle E_{\theta} & = \begin{cases}+90^{\circ}, & \text { for LHCP } \\
-90^{\circ}, & \text { for RHCP. }\end{cases}
\end{aligned}
$$

\section{B. Effects of Ground Plane and Antenna Positions}

To optimize the location of the folded patch GPS antenna,the antenna is tested on a finite ground plane. The circular polarization performance gets changed due to different size of the ground plane. Changes in radius(r) affects the axial ratio (AR).

The antenna receives the satellite signals and passes to the GPS receiver so it can Fig 1.Geometry of the proposed GPS antenna be located outdoors with $360^{\circ}$ view of the sky.

(a) top view and $y-z$ plane view

(b) slotted patch \& (c) meander-strip

\section{Simulation Results}

The compact folded square patch antenna is designed and antenna parameters such as, VSWR, return loss (RL), radiation pattern is simulated using HFSS.

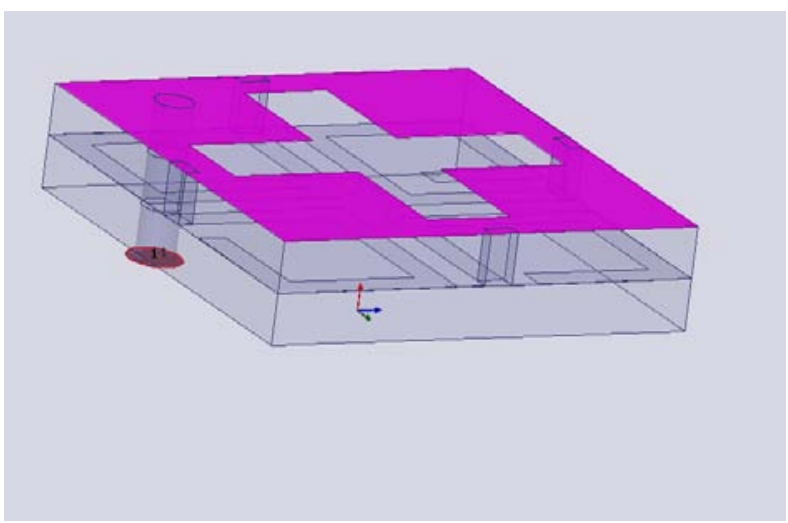

Figure 2: 3-D perspective view of folded square patch GPS antenna
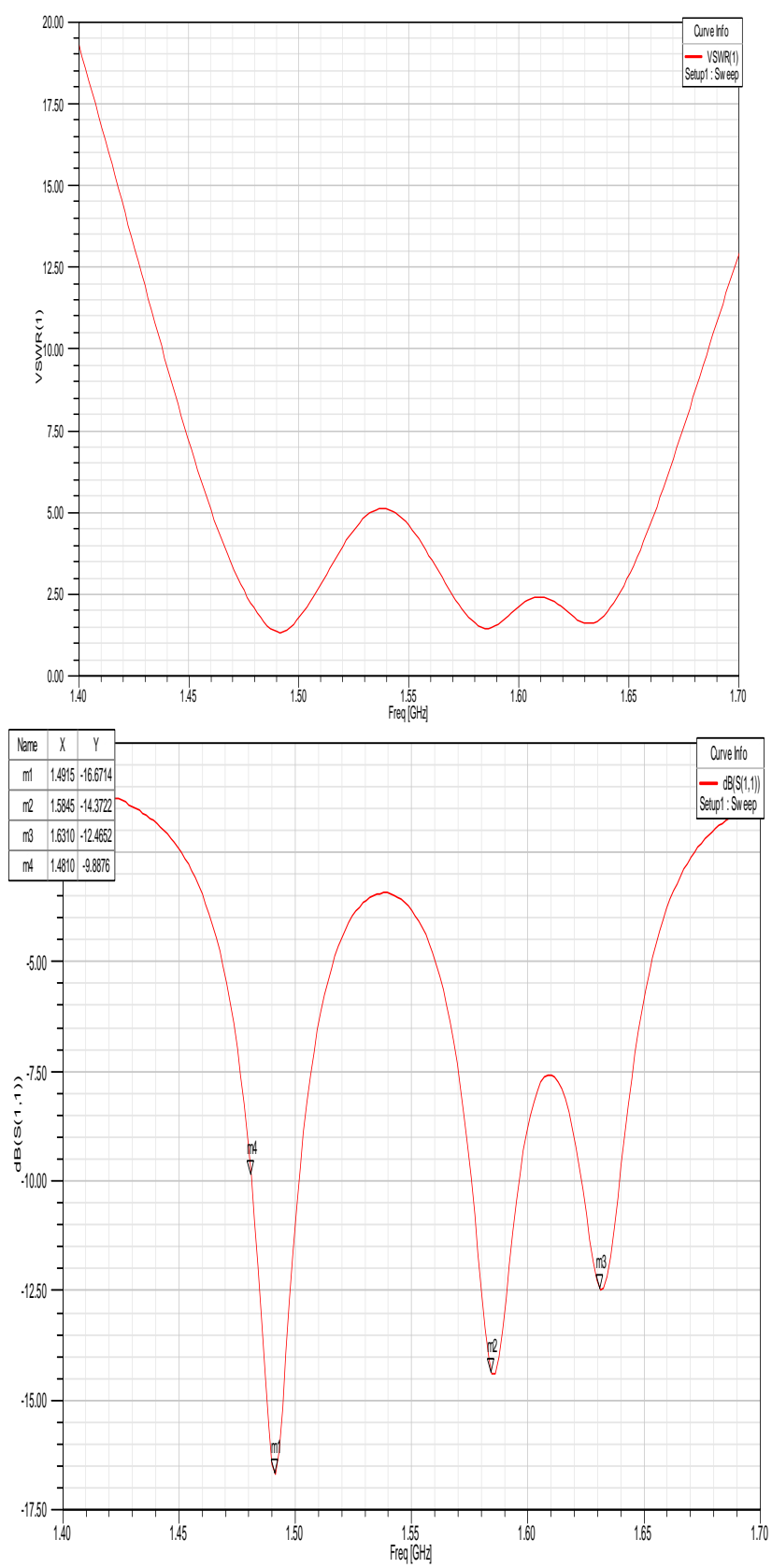

Figure 3: Frequency Vs Return Loss

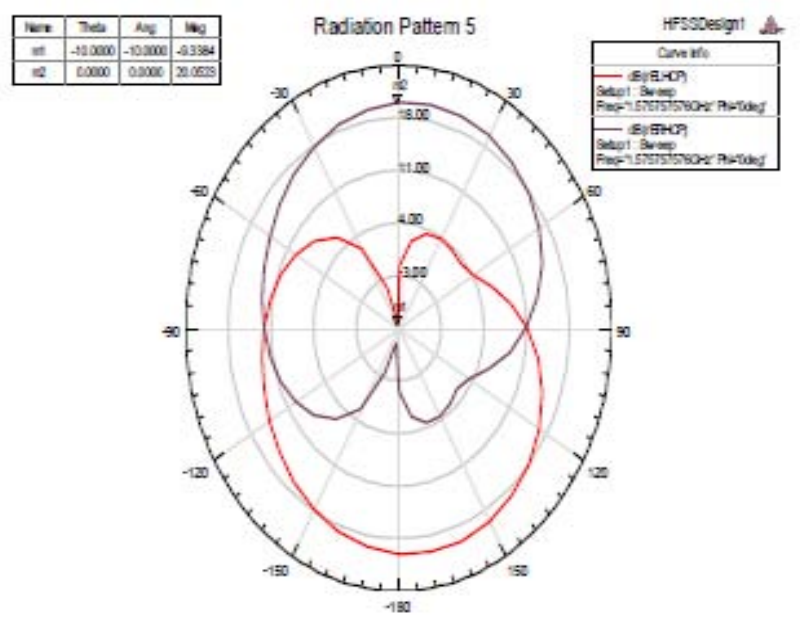

Figure 4: Frequency Vs VSWR Fig 5. Radiation pattern at $1575 \mathrm{MHz}$ 


\section{International Journal of Science and Research (IJSR) \\ ISSN (Online): 2319-7064}

Index Copernicus Value (2013): 6.14 | Impact Factor (2014): 5.611

\section{Conclusions}

The compact circularly polarized folded square patch antenna for GPS applications is designed by the software package HFSS. A good impedance bandwidth and circular polarization is achieved. Several attractive features of this antenna is small size, low cost and stable radiation pattern.

\section{References}

[1] F. Bilotti and C. Vegni, "Design of high-performing microstrip receiving GPS antennas with multiple feeds," IEEE Antennas Wireless Propag. Lett., vol. 9, pp. 248251, 2010.

[2] H. M. Chen and K. L. Wong, "On the circular polarization operation of annular-ring microstrip antennas," IEEE Trans. Antennas Propag.,vol. 47, pp. 1289-1292, Aug. 1999.

[3] H. M. Chen, Y. K. Wang, Y. F. Lin, C. Y. Lin, and S. C. Pan, "Microstrip-fed circularly polarized square-ring patch antenna for GPS applications," IEEETrans. Antennas Propag., vol. 57, no. 4, pp.1264-1267, 2009.

[4] Y. K. Cho, H. D. Kang, S. Y. Hyun, and J. G. Yook, "Gain improvement topology using conical structure for jamming resilient GPS antennas,"inProc. IEEE Antennas Propag. Symp., Jul. 2012.

[5] K. Oh, B. Kim, and J. Choi, "Novel integrated GPS/RKES/PCS antenna for vehicular application," IEEE Microw. Wireless Compon.Lett., vol. 9, pp. 405408, 2010.

[6] R.Leelaratne and R. Langley, "Multiband PIFA vehicle telematics antennas,"IEEE Trans. Veh.Technol., vol. 54, no. 2, pp. 477-485, 2005.

[7] Y. F. Lin, H. M. Chen, F. H. Chu, and S. C. Pan, "Bidirectional radiated circularly polarized squarering antenna for portable RFID reader,'Electron.Lett., vol. 44, no. 24, pp. 1383-1384, 2008.

[8] Y. F. Lin, C. H. Lee, S. C. Pan, and H. M. Chen, "Proximity-fed circularly polarized slotted patch antenna for RFID handheld reader,'IEEETrans.Antennas Propat., vol. 61, no. 10, pp. 5283-5286, 2013.

[9] Y. F. Lin, H. M. Chen, S. C. Pan, Y. C. Kao, and C. Y. Lin, "Adjustable axial ratio of single-layer circularly polarized patch antenna for portable RFID reader," Electron. Lett., vol. 45, no. 6, pp. 290-291,2009.

[10] F. Mariottini, M. Albani, E. Toniolo, D. Amatori, and S. Maci, "Design of a compact GPS and SDARS integrated antenna for automotive applications,"IEEE Antennas Wireless Propag. Lett., vol. 9, pp. 405408,2010.

[11]D.C.Nascimento,R. Schildberg, and J. C. d. S. Lacava, "New considerations in the design of low-cost pro-fed truncated corner microstrip antenna for GPS applications," in Proc. IEEE Antennas Propag. Symp.,Jul. 2007, pp. 749-752.

[12] Nasimuddin, Z. N. Chen, and Z. Qind, "A compact circularly polarized cross-shaped slotted microstrip antenna," IEEE Trans. Antennas Propag., vol. 60, no. 3, pp. $1584-1588,2011$.

[13] X. Tang, H. Wang, Y. Long, Q. Xue, and K. L. Lau, "Circularly polarized shorted patch antenna on high permittivity substrate with wideband,"IEEE Trans. Antennas Propag., vol. 60, no. 3, pp. 1588-1592,2011.

[14] www.antennatheory.com 